\title{
ANÁLISE DE PROJETOS MECÂNICO UTILIZANDO FERRAMENTA DE SIMULAÇÃO CAE
}

\section{MECHANICAL PROJECT ANALYSIS USING SIMULATION TOOL CAE}

\author{
Recebido: 28/03/2016 - Aprovado: 01/06/2016 - Publicado: 30/06/2016 \\ Processo de Avaliação: Double Blind Review
}

\author{
Washington Bueno de Oliveira ${ }^{1}$ \\ Graduando em Tecnologia em Manutenção Industrial \\ Faculdade de Tecnologia de Osasco - Fatec Osasco \\ washingto.b1977@gmail.com \\ André Rosa Ferreira \\ Mestre em Engenharia Elétrica \\ Faculdade de Tecnologia de Osasco - Fatec Osasco \\ andre.rferreira@fatec.sp.gov.br
}

\begin{abstract}
RESUMO: Este estudo visa analisar a frequente quebra do eixo de uma ferramenta utilizada para operações mecânicas de fresagem, para o aumento de sua vida útil e confiabilidade. Será utilizado um software para simulação de $\mathrm{CAE}^{2}$, para análise das propriedades mecânicas do material da peça, seus pontos frágeis e os esforços aplicados. Para a viabilidade do estudo houve alterações na geometria da ferramenta e mudança do material utilizado, buscando melhores resultados nas simulações. Serão utilizados quatro materiais para as simulações aço $S A E^{3}$ 4340, alumínio 7075, aço $S A E 1045$ e aço ferramenta tipo A2. A primeira simulação detectou um ponto de fragilidade na estrutura da peça, após a realização das alterações na estrutura e do material, os resultados obtidos apresentaram uma melhora de aproximadamente de $18 \%$ na deformação plástica no local de cisalhamento.
\end{abstract}

Palavras-Chave: $C A E$; simulação; vida útil; confiabilidade.

\footnotetext{
${ }^{1}$ Autor para correspondência: Faculdade de Tecnologia do Estado de São Paulo, Rua Pedro Rissato, 30, Vila dos Remédios, Osasco - SP, Brasil - CEP 06296-220.

Aço SAE (Society of Automotive Engineers - EUA): classificação normativa dos aços carbono.

${ }^{2}$ Computer Aided Engineerring (CAE) Engenharia assistida por computador é um Software para simulação.

${ }^{3}$ Aço SAE (Society of Automotive Engineers - EUA): classificação normativa dos aços carbono.
} 
ABSTRACT: This study aims to analyze the axis of a tool which is used for mechanical milling operations to increase its life cycle and reliability. It will be used a Software for simulation CAE, for the analysis of the workpiece material mechanical properties, its weaknesses and the applied efforts on it. For the feasibility study there will be made modifications in the geometry of the tool and change the workpiece material, looking after for better results in the simulations. It will be used four materials for steel simulations SAE 4340, 7075 aluminum, steel SAE 1045 steel and A2 tool. The first simulation detected a weak point in the structure part and after the completion of changes in the structure and material, the obtained results showed an improvement of approximately $18 \%$ in plastic deformation on shear location.

Keywords: CAE, simulation; life cycle; reliability.

\section{INTRODUÇÃO}

A confiabilidade de uma máquina ou equipamento é um assunto muito discutido nas indústrias, planos de manutenção preventiva e preditiva utilizando ferramentas de avaliação de desempenho e ou qualidade tais como: FMEA4, 5S5, MCC6, TPM7, RCFA8 entre outros, são os métodos mais usuais implantados em linhas de produção.

Segundo dados obtidos pela pesquisa Documento Nacional de 2013 dispostos no site da associação brasileira de manutenção e gestão de ativos (abraman), 36,27\% dos recursos da manutenção são aplicados em manutenções preventivas e 17,97\% são aplicados em manutenções preditivas, e as três ferramentas da qualidade mais utilizadas são: 5S 23,26\%, MCC $19,25 \%$ e RCFA $17,91 \%$, os dados apontam uma disponibilidade operacional de

\footnotetext{
${ }^{4} \boldsymbol{F M E A}$ - (Modos de Falha e Análise dos Efeitos), visa a análise de falhas potenciais e propõe ações de melhorias com o objetivo de evitar falhas no projeto ou durante o processo.

${ }^{5} \mathbf{5}$ - (Seiri, Seiton, Seiso, Seiketsu e Shitsuke), é uma filosofia empregada em cinco etapas, tendo como metas a conscientização e responsabilidade mutua, disciplina, segurança e produtividade no ambiente de trabalho.

${ }^{6}$ MCC - (Manutenção Centrada em Confiabilidade), tem seu foco em um planejamento de manutenção sistemático considerando aspectos de confiabilidade.

${ }^{7} \boldsymbol{T P M}$ - (Manutenção Produtiva Total), é um sistema de gerenciamento que conta com auxílio dos colaboradores para a melhoria continua de plantas e equipamentos.

${ }^{8} \boldsymbol{R C F A}$ - (Análise das Causas Raízes de Falha), é um processo que identifica a causa raiz de uma falha ocorrida no equipamento, e com base nas informações obtidas são formuladas ações para evitar falhas futuras.
} 
89,29\%. Considerando essas informações e tomando como base que o equipamento tenha um plano de manutenção de excelência, e seus componentes sejam substituídos obedecendo as recomendações do fabricante em relação à margem de confiabilidade e vida útil, com a análise de CAE, será possível avaliar o projeto dos componentes em suas aplicações e simulando os esforços sofridos no ambiente de trabalho, visualizando seus pontos frágeis, aplicar possíveis alterações para o aumento da confiabilidade da peça.

Tomando como base este conceito o estudo será realizado em um eixo de uma ferramenta de fresar raios e tem o objetivo de proporcionar o aumento da vida útil com a aplicação da análise de CAE, impactando diretamente no aumento da disponibilidade da máquina com a diminuição das horas de setup9.

Com a informação detalhada representada em CAD10, muitos processos CAE podem agora ser aplicada em conjunto para ajudar a garantir a qualidade e rápida revisão de projeto. Isto permite a utilização total das valiosas ferramentas modernas de modelagem e visualização de CAD paramétricos além de recursos de análise para determinar as características de desempenho, tais como a interferência do componente e propriedades do sistema dinâmico. (CROSHECK, 1997).

O eixo é confeccionado em aço SAE 4340, temperado e revenido com uma dureza entre 48 e $50 H R C^{11}$. O aço $S A E 4340$ (aço para construção mecânica), se caracteriza por ter elevada temperabilidade, resistência à fratura e à fadiga.

Após a primeira simulação serão avaliados os pontos frágeis da peça e uma possível alteração para a correção das fragilidades será realizada. Após a reavaliação do eixo alterado novas simulações serão feitas trocando o material original do eixo.

\section{TEMAS RELATIVOS AO REFERENCIAL TEÓRICO QUE CONSIDERAR RELEVANTE}

\subsection{CLASSIFICAÇÃO DAS LIGAS DE ALUMÍNIO}

A matéria prima para a produção do alumínio é a bauxita que apresenta cerca de $60 \%$ de óxido de alumínio $\left(\mathrm{Al}_{2} \mathrm{O}_{3}\right)$. A bauxita é submetida a um processo químico para a obtenção

\footnotetext{
${ }^{9}$ Setup: medida de tempo para a troca de uma ferramenta ou preparação do equipamento para produção.

${ }^{10}$ CAD Computer Aided Design computador auxiliando no projeto.

${ }^{11}$ HRC (Dureza Rockwell C): é uma base de medida para classificar a dureza do aço, podendo assim, classificar resistência mecânica e a resistência ao desgaste do material.
} 
do óxido de alumínio, que por sua vez passa por um processo de eletrólise. Por ter uma massa especifica três vezes menor que a do aço o alumínio é uma das ligas metálicas mais leves do mercado, possuindo boa condutividade elétrica e térmica, outra característica importante do alumínio é sua resistência à corrosão atmosférica em seu estado mais puro.

O alumínio em seu estado puro não oferece bons resultados em sua eficiência mecânica, mas pelo fato de que à liga de alumínio podem ser combinados diferentes materiais, sua resistência mecânica pode ser modificada com a adição de elementos de liga, como cobre $(\mathrm{Cu})$, manganês $(\mathrm{Mn})$, silício $(\mathrm{Si})$, magnésio $(\mathrm{Mg})$, zinco $(\mathrm{Zn})$, que são classificados como os principais elementos de liga do alumínio e são caracterizados como o primeiro algarismo da classificação, por exemplo:

- $\quad$ 1XXX maior que 99\% Alumínio (AL);

- $\quad 2 X X X \mathrm{Cu}$;

- $\quad 3 X X X \mathrm{Mn}$;

- $\quad 4 X X X ~ S i$

- $\quad 5 X X X \mathrm{Mg}$;

- $\quad 6 X X X \mathrm{Mg}+\mathrm{Si}$;

- $\quad 7 X X X \mathrm{Zn}+\mathrm{Mg}$;

- $\quad$ XXXX outros.

O segundo Algarismo X indica a adição de elementos de liga ou o controle de algum tipo de impureza. Pequenas quantidades de ferro são constantes na composição da liga de alumínio e elementos como o cromo $(\mathrm{Cr})$, chumbo $(\mathrm{Pb})$, zircônio $(\mathrm{Zr})$, titânio $(\mathrm{Ti})$ ou níquel (Ni) podem ser adicionados.

Para a simulação foi adotada a liga de alumínio da série 7XXX, em particular a liga 7075 por apresentar em sua composição química elementos como $\mathrm{Cr}, \mathrm{Cu}$, ferro (Fe), $\mathrm{Ti}$, $\mathrm{Ni}, \mathrm{Mn}, \mathrm{Si}$, zircônio (Zr) dentre outros. Esses elementos empregam uma alta resistência mecânica à liga de alumínio, semelhante ao aço estrutural.

\subsection{CLASSIFICAÇÃO DAS LIGAS DE AÇO}

Podemos classificar o aço como uma liga de ferro com até 2,0\% de carbono (C), em sua composição química, podendo ser adicionados outros elementos em sua liga, como o $\mathrm{Cr}$, 
Mn, Si, molibdênio (Mo), Ti, Ni, vanádio (V), nióbio (Nb), tungstênio (W). Elementos como fósforo (P), Si e enxofre (S) são provenientes do processo de fabricação e são conhecidos como elementos residuais.

Características como dureza, tenacidade e ductilidade podem ser controladas com a adição de elementos de liga na estrutura do aço combinados com tratamentos térmicos, o que faz com que as ligas de aço tenham aplicações ilimitadas dentre os processos mecânicos.

Há quase um século, os aços são os materiais industriais mais amplamente empregados... O papel de destaque do aço é evidente. Possivelmente, o principal fator que levou o aço a ocupar este papel preponderante na engenharia é o amplo espectro de propriedades e características de desempenho que pode ser obtido a custos baixos... (SILVA; MEI, 2010).

A classificação dos aços não segue um único critério específico, o aço pode ser classificado conforme sua microestrutura, composição química, processo ou aplicação. Segundo a denominação normativa SAE (Society of Automotive Enginners), a classificação do aço é dada por quatro números, nos quais os dois primeiros algarismos indicam a família do aço e os dois últimos algarismos indicam o teor centesimal de porcentagem $(0,01 \%)$, presentes na microestrutura, por exemplo: Aço $S A E$ 4340, os dois primeiros algarismos $43 \mathrm{XX}$, indicam que o aço é composto por $\mathrm{Ni} 1,82 \%$, Cr entre 0,50 e $0,80 \%$ e Mo 0,25\%, enquanto os dois últimos algarismos YY40, indicam a quantidade de carbono em sua estrutura 0,4\%, caracterizando como um a aço $S A E 4340$ níquel cromo molibdênio, indicado para peças com alta solicitação mecânica, elevada temperabilidade e alta tenacidade.

$\mathrm{O}$ aço $S A E 1045$ é composto por C entre 0,43 e $0,50 \%$, Si entre 0,15 e $0,35 \%, \mathrm{Mg}$ entre 0,30 e $0,60 \%, P$ P $0,03 \%$ e S $0,05 \%$. Possuindo uma boa relação entre resistência mecânica e resistência à fratura, sua dureza de trabalho pode variar entre 180 e $350 H B$, sendo indicado para a fabricação de peças para a indústria mecânica em geral.

Aços ferramentas tipo A2 tem em sua composição química C 0,96\%, Mn 0,60\%, Cr $4,90 \%$, Mo $0,92 \%, \mathrm{~V} 0,17 \%$, outros $0,30 \%$, geralmente usado para tralho a frio, com uma dureza de trabalho elevada, entre 53 a $58 H R C$, é indicado para peças ou ferramentas que exijam alta resistência ao desgaste.

Uma definição exata de aço ferramenta, satisfatória tanto para o usuário como para o produtor, é praticamente impossível. Enquanto, para o leigo, qualquer aço utilizado para fabricar uma ferramenta é um aço ferramenta, grande quantidade de aços 
considerados aços ferramentas pelos produtores é vendida para aplicações diversas, que não a de fabricação de ferramentas. (SILVA; MEI, 2010).

\section{MÉTODO OU METODOLOGIA}

Para o início da análise foram realizadas duas pesquisas exploratórias, a primeira teve o objetivo de coletar dados sobre as ferramentas da qualidade utilizadas pela indústria nacional para o aumento da confiabilidade das máquinas e equipamentos. A segunda pesquisa teve como base as ligas metálicas. Durante a pesquisa foram avaliados elementos como aplicações, composição química e resistência mecânica.

As ligas selecionadas para o projeto foram: alumínio série 7075, seus elementos de liga proporcionam uma elevada resistência mecânica e é de fácil usinabilidade; o aço $S A E$ 1045 é considerado um aço de fácil acesso de mercado, aço ferramenta tipo A2, seus elementos de liga proporcionam dureza elevada, resistência à oxidação, resistência elevada ao desgaste e boa usinabilidade.

O processo de seleção de aços para determinada aplicação deve levar em conta, então, não somente as propriedades dos aços presentemente disponíveis em comparação com os materiais alternativos, como as tendências de desenvolvimento na própria indústria do aço. A seleção é, portanto, um processo dinâmico e deve ser revisto, periodicamente, se os melhores resultados são desejados. (SILVA; MEI, 2010).

Após a definição das ligas a serem utilizadas na simulação, uma cópia do eixo foi reprojetado com o auxílio do software Soldworks, respeitando as dimensões e material do eixo original (figuras $\mathrm{n}^{\circ} 1$ ). Segundo o roteiro da peça, o eixo deve ser confeccionado em aço $S A E$ 4340 e depois de usinado deve ser temperado e revenido, segundo as normas estabelecidas da relação tempo e temperatura por milímetro de material para atingir uma dureza entre 48 a 50 HRC.

A única ressalva a ser feita é com relação ao tratamento térmico aplicado no eixo original. Por não ter a opção do tratamento térmico aplicado na peça original optou-se em utilizar um aço $S A E 4340$ normalizado para a simulação. 


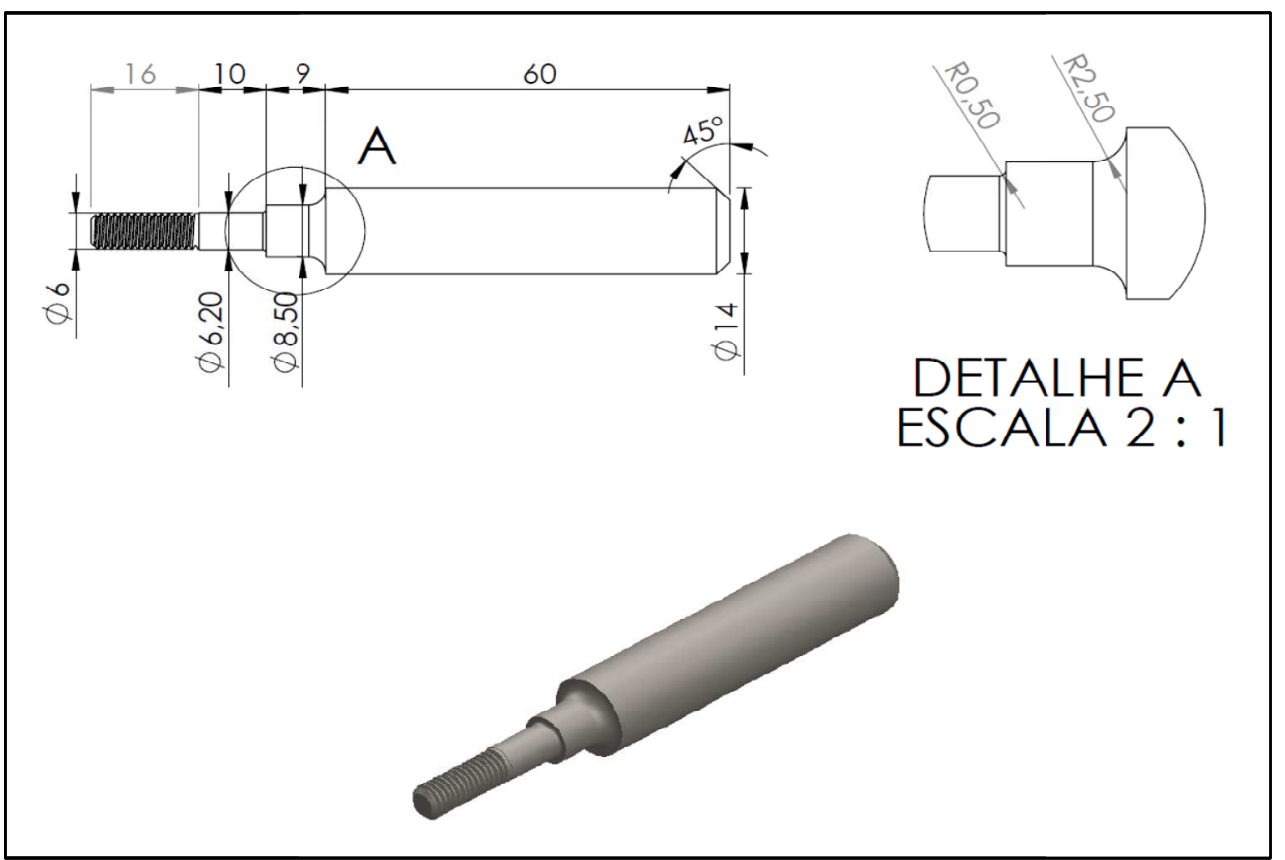

Figura 1- Dimensões do eixo - fonte recriada pelo autor

Com a nova proposta de projeto para o eixo, foi utilizada a ferramenta Simulation Xpress Study, (responsável em gerar a simulação no software Solidworks), para simular os pontos de fixação do eixo na máquina de fresar e a força aplicada na ferramenta durante a operação de trabalho. Para todas as simulações foi adotada uma força de $100.000 \mathrm{~N}$ (Newtons) nos mesmos pontos de fixação.

\section{RESULTADOS}

A simulação realizada no eixo usinado com as dimensões originais em aço $S A E 4340$ apresentou acúmulo de tensões no local de fixação da ferramenta de fresagem (representado na figura $\mathrm{n}^{\circ} 2$ ). $\mathrm{O}$ acúmulo de tensões pode provocar o surgimento trincas gradualmente, causando o cisalhamento do eixo provocando assim a quebra da ferramenta. 


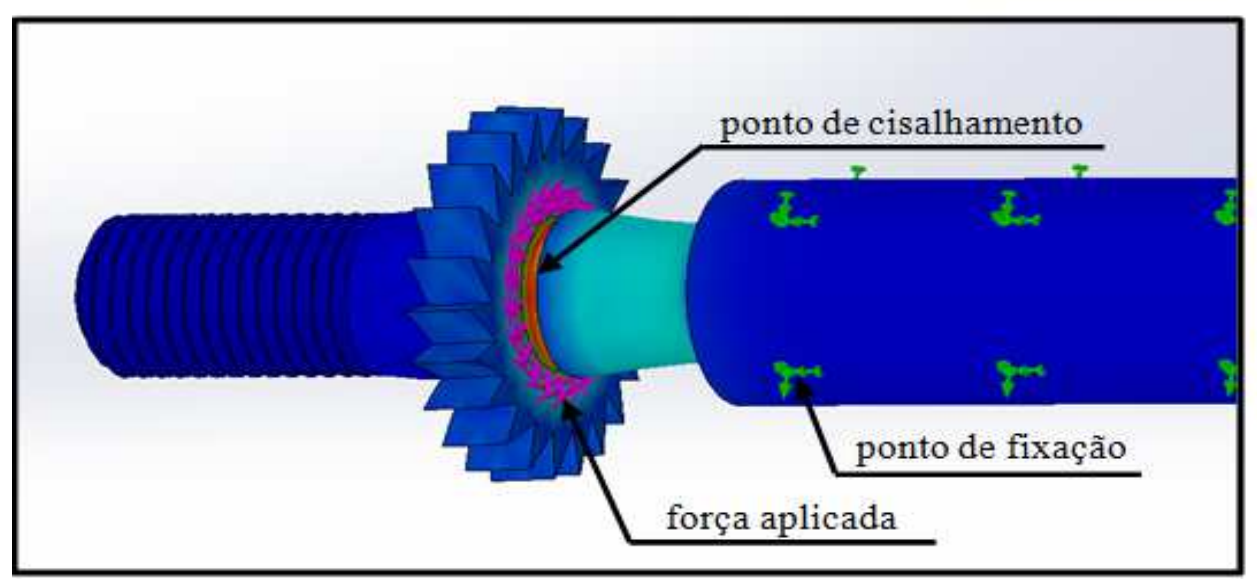

Figura 2 - Ponto de Cisalhamento, liga de aço 4240, raio de 0,5mm (eixo original)

Fonte: elaborado pelo autor

O local de acúmulo de tensões detectado na simulação coincide com o ponto de cisalhamento sofrido pelo eixo no final da sua vida útil. Para minimizar o acúmulo de tensões foi feita a alteração do raio de concordância do ponto de fixação da fresa passando de $0,5 \mathrm{~mm}$ para $1 \mathrm{~mm}$, representado na figura $\mathrm{n}^{\mathbf{0}} 3$.

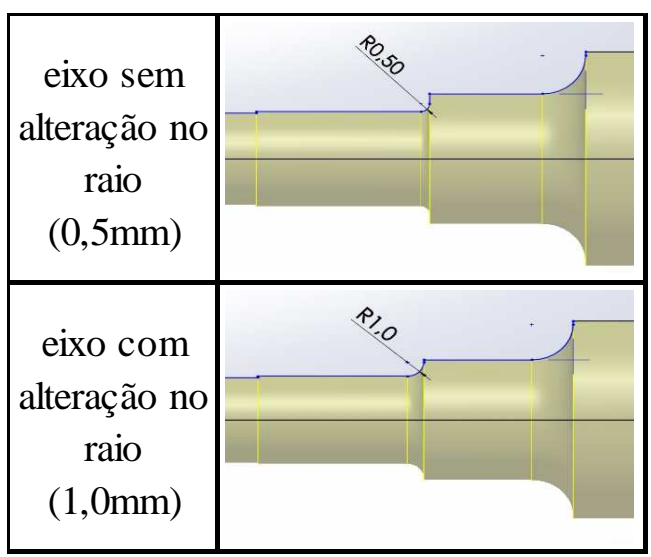

Figura 3 - Detalhe da alteração do raio - Fonte: Elaborado pelo autor.

Com o objetivo de aumentar a vida útil do eixo, além da alteração do raio foram realizadas simulações utilizando as seguintes ligas metálicas: alumínio série 7075, aço $S A E$ 1045, aço ferramenta tipo A2. Os resultados obtidos estão demonstrados na tabela ${ }^{\circ} 1$. 


\begin{tabular}{|c|c|c|c|c|c|c|}
\hline \multicolumn{2}{|c|}{ Material } & $\begin{array}{c}\text { Aço 4340 Norm. } \\
\text { (raio de 0,5mm) }\end{array}$ & $\begin{array}{c}\text { Aço } 4340 \text { Norm. } \\
\text { (raio de 1,0mm) }\end{array}$ & $\begin{array}{c}\text { Alumínio Série } 7075 \\
\text { (raio de 1,0mm) }\end{array}$ & $\begin{array}{c}\text { Aço } 1045 \text { Trefilado } \\
\text { (raio de 1,0mm) }\end{array}$ & $\begin{array}{c}\text { Aço Ferramenta Tipo } \\
\text { A2 (raio de 1,0mm) }\end{array}$ \\
\hline \multirow{2}{*}{$\begin{array}{c}\text { Tensão de } \\
\text { Von Mises }\end{array}$} & min. & $1,5519 \mathrm{KPa}$ & $1,1782 \mathrm{KPa}$ & $738,7 \mathrm{~Pa}$ & $682,2 \mathrm{~Pa}$ & $489 \mathrm{~Pa}$ \\
\cline { 2 - 7 } & máx. & $736,023 \mathrm{GPa}$ & $602,906 \mathrm{GPa}$ & $602,852 \mathrm{GPa}$ & $603,098 \mathrm{GPa}$ & $603,129 \mathrm{GPa}$ \\
\hline $\begin{array}{c}\text { Limite de } \\
\text { escoamento }\end{array}$ & Total & $710 \mathrm{M}$ & $710 \mathrm{M}$ & $95 \mathrm{M}$ & $530 \mathrm{M}$ & - \\
\hline $\begin{array}{c}\text { Deslocament } \\
\text { o Resultante } \\
(\mathrm{mm})\end{array}$ & min. & $1.000 \mathrm{e}-030$ & $1.000 \mathrm{e}-030$ & $1.000 \mathrm{e}-030$ & $1.000 \mathrm{e}-030$ & $1.000 \mathrm{e}-030$ \\
\cline { 2 - 7 } & máx. & $3.520 \mathrm{e}+001$ & $3.319 \mathrm{e}+001$ & $9.514 \mathrm{e}+001$ & $3252 \mathrm{e}+001$ & $3.273 \mathrm{e}+001$ \\
\hline
\end{tabular}

As simulações realizadas com a modificação na estrutura do raio e alteração das ligas metálicas do eixo apresentaram uma redução de aproximadamente $18 \%$ no acúmulo máximo da tensão de Von Mises ${ }^{12}$. Como apresentado no gráfico n ${ }^{\circ} 1$.

As simulações realizadas com a alteração da estrutura do eixo e ligas metálicas diferentes apresentaram resultados semelhantes conforme figura $\mathrm{n}^{\circ} 4$, mas analisando os resultados em um gráfico de tendências, observa-se que as ligas de aço $S A E 4340$ e alumínio série 7075, são as mais indicadas para a construção do eixo, como mostra a gráfico $\mathrm{n}^{\circ} 2$.

\footnotetext{
${ }^{12}$ Tensão de Von Mises: pode ser definido como o acumulo máximo de energia sofrido por uma peça quando aplicada uma força causando a deformação da estrutura.
} 
Tensão de Von Mises máx

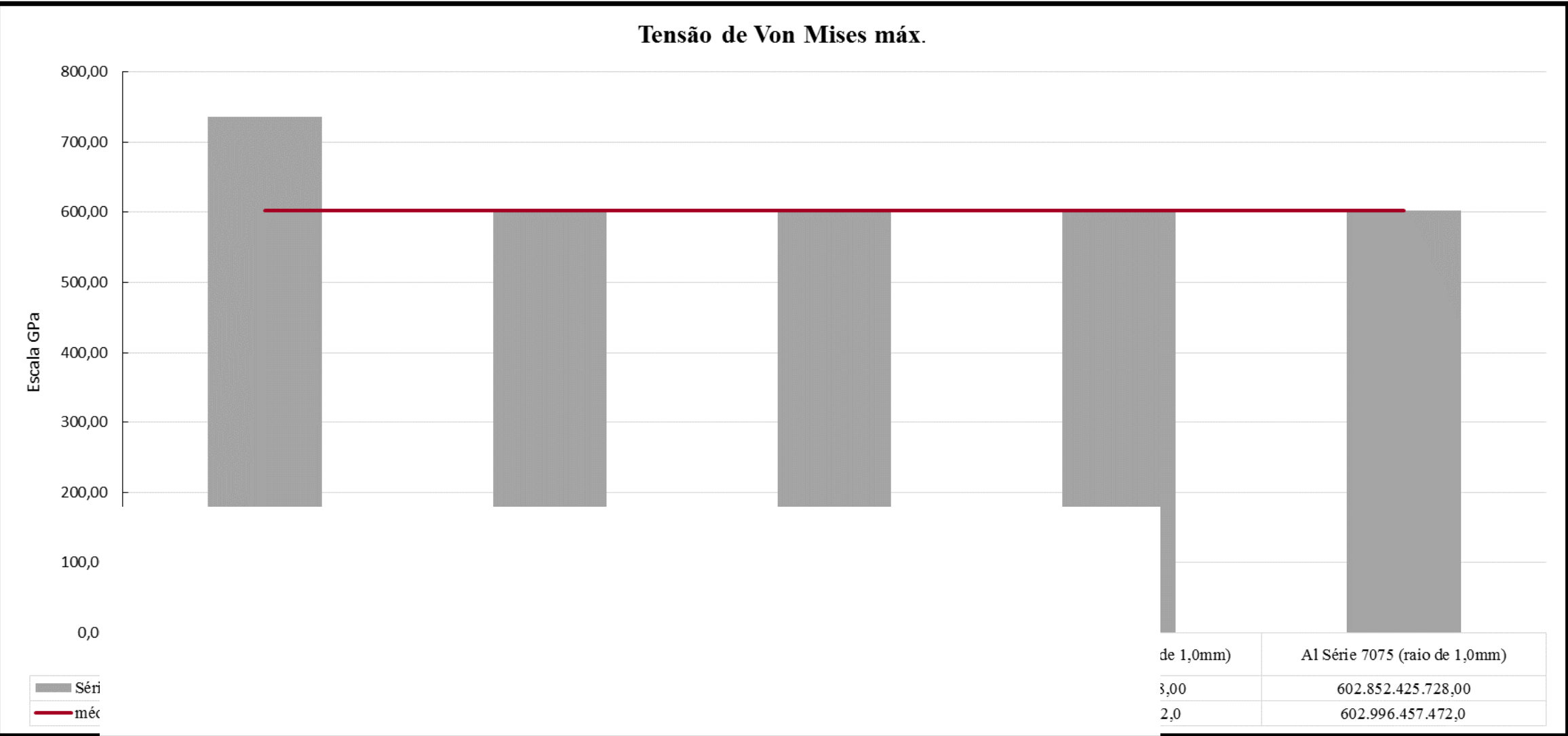

REMIPE- Revista de Micro e Pequenas Empresas e Empreendedorismo da Fatec Osasco V. 2, $\mathrm{N}^{\circ} 1$, jan.-jun. 2016. 


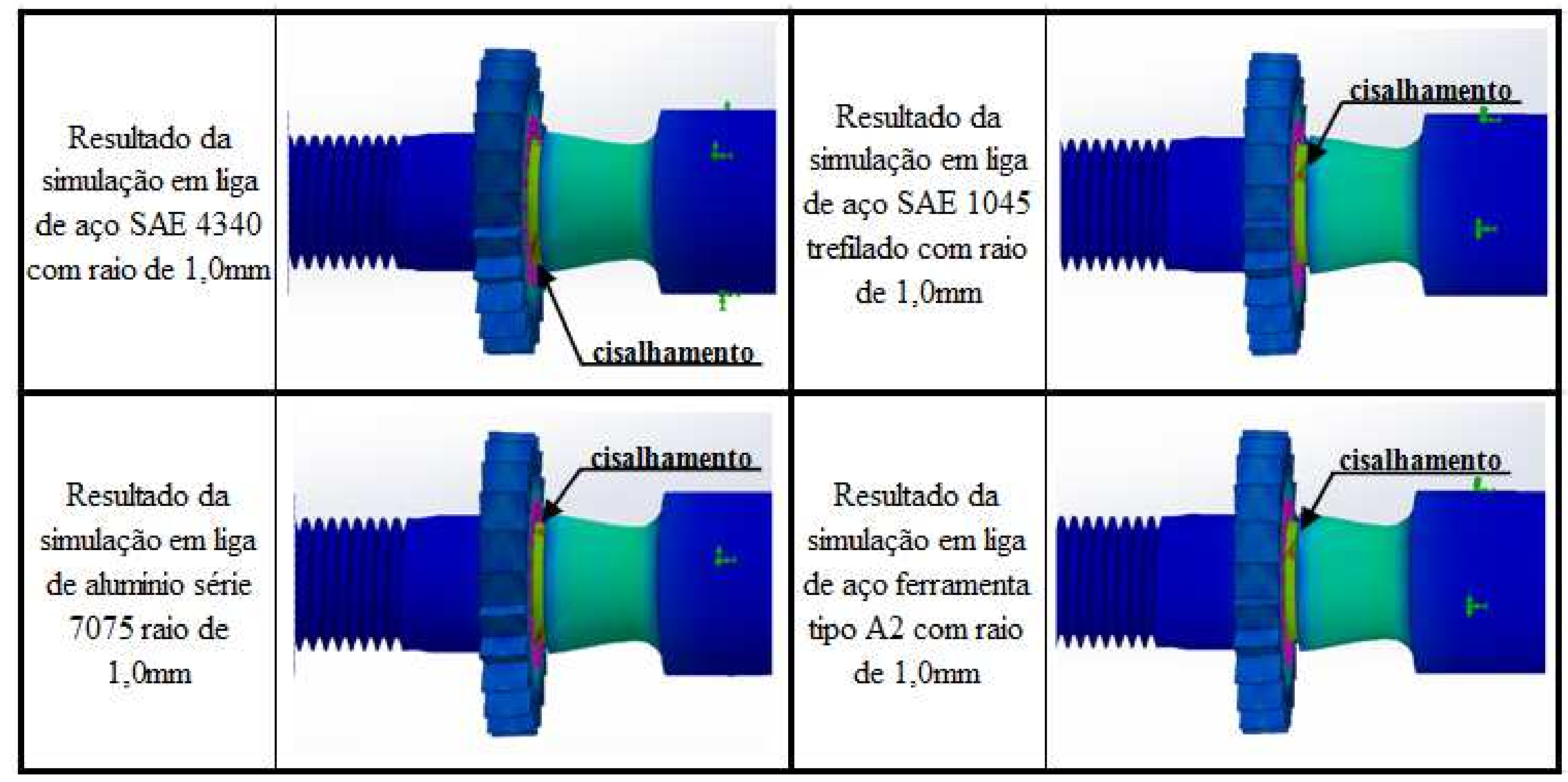

autor. 


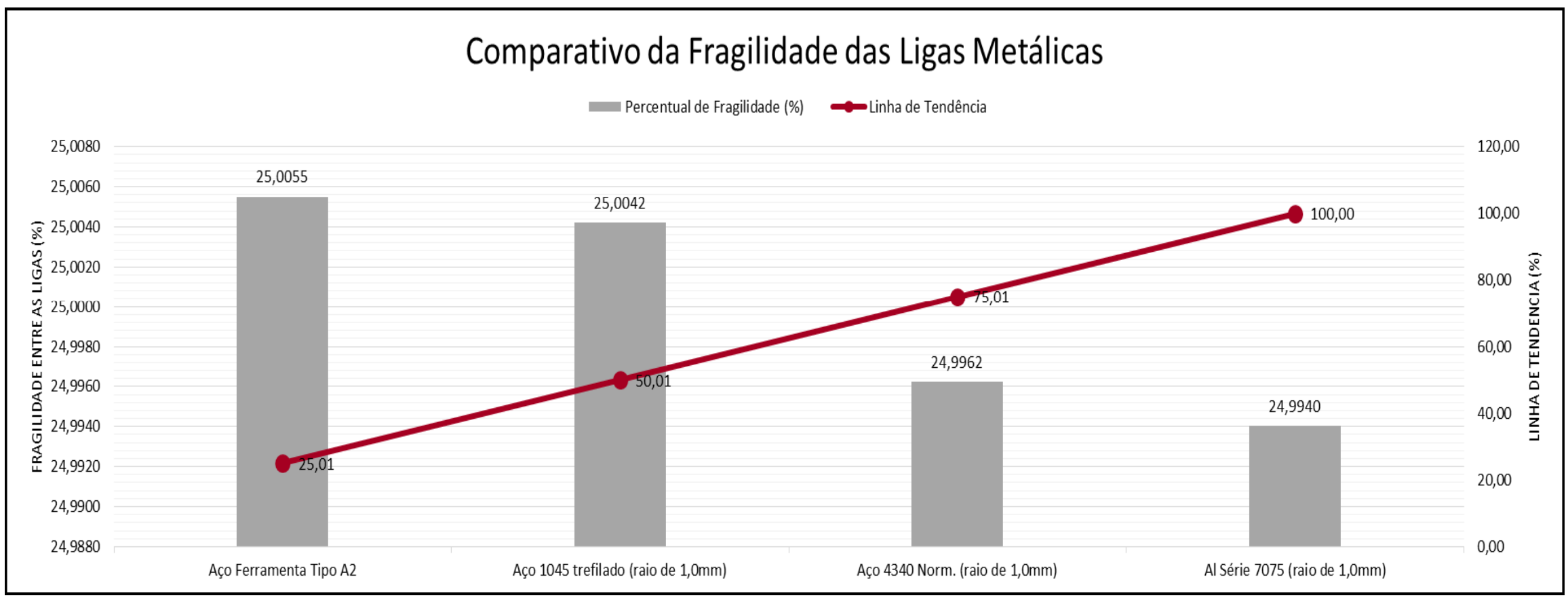




\section{CONSIDERAÇÕES FINAIS}

Cada vez mais a manutenção industrial utiliza ferramentas para aumentar a confiabilidade de máquinas e equipamentos. Os planos de manutenção preventiva e preditiva são constantemente reavaliados para medir sua eficácia. Outra maneira de aumentar a produtividade está relacionada diretamente ao tempo de setup: quanto menor for o tempo empregado na troca de uma ferramenta e preparação do equipamento, maior será o tempo em que a máquina estará em produção.

A análise de $C A E$ desenvolvida teve como objetivo elevar a confiabilidade de uma máquina/ferramenta considerando que seu funcionamento está em condições ideais. Com o auxílio do software de simulação, foi possível avaliar os esforços aplicados na estrutura do eixo durante a operação mecânica de fresagem, identificando as deformações plásticas sofridas pela liga metálica, e propor uma alteração na sua geometria que resultou na diminuição das tensões acumuladas aumentando a vida útil do eixo e confiabilidade do equipamento.

A alteração feita na geometria da ferramenta proporcionou uma redução de aproximadamente $18 \%$ nas tensões acumuladas, e com a aplicação de outras ligas metálicas obteve-se a diminuição desse valor, aumentando a resistência mecânica à deformação plástica do eixo.

O melhor material para confecção de um novo eixo é a liga de alumínio série 7075 , pois apresentou o menor acúmulo de tensões na área onde ocorre o cisalhamento do eixo, caracterizando uma resistência maior ao surgimento de trincas por fadiga mecânica, porém não é muito indicado na utilização de ferramental. Sendo assim o melhor resultado foi a utilização da liga de aço SAE 4340 diminuindo em $18 \%$ as tensões da peça original.

O aumento da vida útil do eixo além de impactar diretamente na diminuição de horas de setup e no aumento da confiabilidade do equipamento proporcionou a diminuição nos gastos de manutenção. 


\section{REFERÊNCIAS}

ASSOCIAÇÃO BRASILEIRA DE MANUTENÇÃO E GESTÃO DE ATIVOS (ABRAMAN). Documento Nacional 2013. Disponível em: <http://www.abraman.org.br/Arquivos/403/403.pdf>. Acesso em: 26 de fev. 2016.

ASSOCIAÇÃO BRASILEIRA DO ALUMÍNIO (ABAL). Características Químicas e Físicas. Disponível em: <http://www.abal.org.br/aluminio/caracteristicas-quimicas-efisicas/>. Acesso em: 29 de fev. 2016.

CROSHECK, James E. (ED). ASM Handbook digital. The Volume Chair was George E. Dieter. ASM International Handbook Committee, 1997. v. 20, p. 407.

GGD METALS. Alumínios. Disponível em: 〈http://www.ggdmetals.com.br/>. Acesso em: 01 de mar. 2016.

INFOMET. Alumínio e suas ligas. Disponível em: <http://www.infomet.com.br/site/metaise-ligas-conteudo-ler.php?codAssunto=108>. Acesso em: 02 de mar. 2016.

MSPC INFORMAÇÕES TÉCNICAS. Alguns metais não ferrosos I-10. Disponível em: <http://www.mspc.eng.br/ciemat/metnfer110.shtml>. Acesso em: 02 de mar. 2016.

SIEMENS. CAE / Engenharia Auxiliada por Computador. Disponível em: <http://www.plm.automation.siemens.com/pt br/plm/cae.shtml $>$. Acesso em: 29 de fev. 2016.

SILVA, André Luiz V. da Costa e.; Mei, Paulo Roberto. Aços e ligas especiais. 3. ed. São Paulo: Blucher, 2011, p. 317, 318, 363, 364.

VILLARES METALS. Aço Ferramenta para Trabalho a Frio. Disponível em: <http://www.villaresmetals.com.br/pt/Produtos/Acos-Ferramenta/Trabalho-a-frio/VA2>. Acesso em: 02 de mar. 2016. 